\title{
A vision for future hydrologic modelling to support Victoria's evolving water resource management
}

\author{
$\underline{\text { Seker Mariyapillai }}{ }^{a}$, Uttam Manandhar ${ }^{a}$ and Tony Sheedy ${ }^{b}$ \\ ${ }^{a}$ Department of Environment, Land, Water and Planning, Victoria, ${ }^{b}$ WaterRes Pty Ltd \\ Email: Seker.Mariyapillai@delwp.vic.gov.au
}

\begin{abstract}
The development and management of Victoria's water resources has undergone major changes as the supply system was developed, entitlements and property rights were established and diversions grew. The growth of diversions, particularly within the Murray-Darling Basin, was not sustainable. These changes were major drivers of the process of water reform which was begun in 1994. The impact of the water reform on Victoria's water supply systems has been important and created many opportunities to sustainably manage water resources. These included a cap (or limit) on diversions, the separation of entitlements from land, the establishment of a water market, improved efficiency in water use and the recent Murray-Darling Basin Plan water recovery to better protect the environment. These water reforms have resulted in water supply systems becoming far more complex to manage, operate and meet compliance. For example, the local irrigation areas had a defined boundary prior to water reform. There was fixed number of licences attached to the land and allocations to those licences. Now, water that may once have been used for irrigation in one irrigation area may be traded and used for consumptive as well as non-consumptive purposes in other areas within a connected system or vice versa, for example the southern connected Murray-Darling Basin and Melbourne system.
\end{abstract}

As the regulatory framework has evolved over the past twenty-five years, so too has water demand patterns of all users. For irrigators, this has included adapting irrigation practices to manage their water entitlement usage, manage their risk and improve their water use efficiency. Victoria has also invested significantly in the modernisation of the irrigation distribution system itself to minimise distribution losses and recover water. Urban use has changed with improved water efficiencies and alternative sources of supply such as storm water, rainwater tanks and recycled water. New environmental entitlements have been created to deliver environmental outcomes. There are delivery capacity constraints to consider as competing water demand patterns change including both consumptive use as well as the large-scale delivery of environmental water.

Throughout the process of water reform, hydrologic modelling has been continuously developed to cope with real world changes and played a key role to inform policy and compliance framework. Moving forward, modern software tools and technology are required to meet water industry needs to model the system as it is now and may be in the future. Victoria contributed to the development of the National Hydrological Modelling Strategy (NHMS) to plan for its modelling requirements. The NHMS ensures that Australia's hydrologic modelling capability, community and software is ready to meet the priority hydrological modelling needs of Australian governments. Source is a modelling tool that has been developed within the NHMS. Victoria has implemented Source in many valleys including the foundational model of Goulburn, Broken, Campaspe, Coliban and Loddon system, and is developing Source models for other parts of Victoria.

Looking forward, there is a need and an opportunity for the hydrological models to be applied in a transparent, repeatable and defensible way for a wide range of applications with different purposes such as: (i) a planning model to support water management practices including assessing alternatives sources for urban water supply, catchment modelling of climate change and land use change, (ii) an operational model which may input live climate and streamflow data feeds for flow and demand forecasting, (iii) a tool for compliance which at a basin or state level requires modelling, (iv) environmental flow delivery, flooding issues, delivery capacity and salinity assessments, and (v) a planning as well operational tool to manage the movement of water through the water grid across the jurisdictions to meet competing water demand.

Source, a modern software, provides a platform for ongoing development and improvement to meet modelling needs across Australia. Challenges for future modelling, including representing complex interconnected systems, water trade, environmental requirements and accounting of water across all water users in a system with no boundaries and a continuously changing landscape. It is expected that the next generation of hydrological models, that leverage the Source software will provide a mechanism to explicitly or implicitly support analysis of a wide range of impacts of water management.

Keywords: Hydrologic modelling, NHMS, water, Victoria, Source 
Mariyapillai et al., A vision for future hydrologic modelling to support Victoria's evolving water resource management

\section{INTRODUCTION}

Hydrologic modelling involves simulating numerous aspects of hydrology as well as water sharing arrangements, system operations and modern water accounting frameworks. It includes simulating rainfall-runoff catchment processes and the modelling of the storage, distribution and use of water resources and flow in waterways. The distribution and use of water resources can be reasonably simple in small unregulated river systems and very complex in large regulated rivers and water supply systems. In Victoria, the sharing of water resources is governed by established rights including bulk entitlements and individual water shares.

Hydrologic modelling has played a very important role to inform water management policy in Victoria to date. As Victoria's water infrastructure, management and policies continue to evolve, hydrologic modelling is also evolving to meet the emerging challenges and to continue to provide information to support water resource management decisions. This paper reflects on the development of Victorian water resource management and the hydrologic modelling that supported it and considers recent developments and emerging trends that will drive hydrologic modelling requirements into the future.

\section{BACKGROUND}

The development and management of Victoria's water resources has undergone major changes through the twentieth century and continues to this day. The mid-twentieth century saw major infrastructure built to harvest and distribute water for irrigation and urban purposes. This included over 7000 GL of storage capacity built in northern Victoria between 1950 and 1980. The storages formed part of the water supply system to supply water for irrigation to licences which were tied to the land. As the supply system was developed, the diversions for irrigation continued to grow. The continued growth of diversions in Victoria and in other Murray-Darling Basin jurisdictions was not sustainable. These changes were major drivers of the process of water reform which was begun in Victoria in 1994 when the Council of Australian Governments (COAG) announced a Water Reform Framework.

The COAG water reform framework required the development of a comprehensive system of water allocations and entitlements. Tisdell et al (2002) state that the principles establishing a strategic framework for the implementation of property rights in water included:

1. That all consumptive and non-consumptive water entitlements be allocated and managed in accordance with comprehensive planning systems and based on full basin-wide hydrologic assessment of the resource.

2. That water entitlements and institutional arrangements be structured so as not to impede the effective operation of water markets and such that, as far as practicable, trading options associated with property rights in water reside with the individual end users of water.

3. That water entitlements be clearly specified in terms of:

- rights and conditions of ownership tenure;

- $\quad$ share of natural resource being allocated (including probability of occurrence);

- details of agreed standards of any commercial services to be delivered;

- constraints to and rules on transferability; and

- constraints to resource use of access.

While the COAG reform along with reforms in Victorian water industry (Figure 1) has led to major changes to Victoria's water supply systems, physically and operationally, these have created many benefits such as a cap on diversions, the establishment of water entitlements and associated property rights including their separation from land, the establishment of a water market, and improved efficiency in the allocation of water for uses including irrigation, urban and the environment.

These reforms and changes have resulted in water supply systems becoming far more complex. For example, prior to water reform, local irrigation areas had a defined boundary - there was a fixed amount of land, fixed amount of licences attached to land, allocations to those licences and water was used in that local area. Now, water that may once have been allocated to water users in a given local area may trade that water and it may be used for consumptive as well as non-consumptive purposes in other areas within a connected system or vice versa, for example the southern connected Murray-Darling Basin and Melbourne. 
Mariyapillai et al., A vision for future hydrologic modelling to support Victoria's evolving water resource management

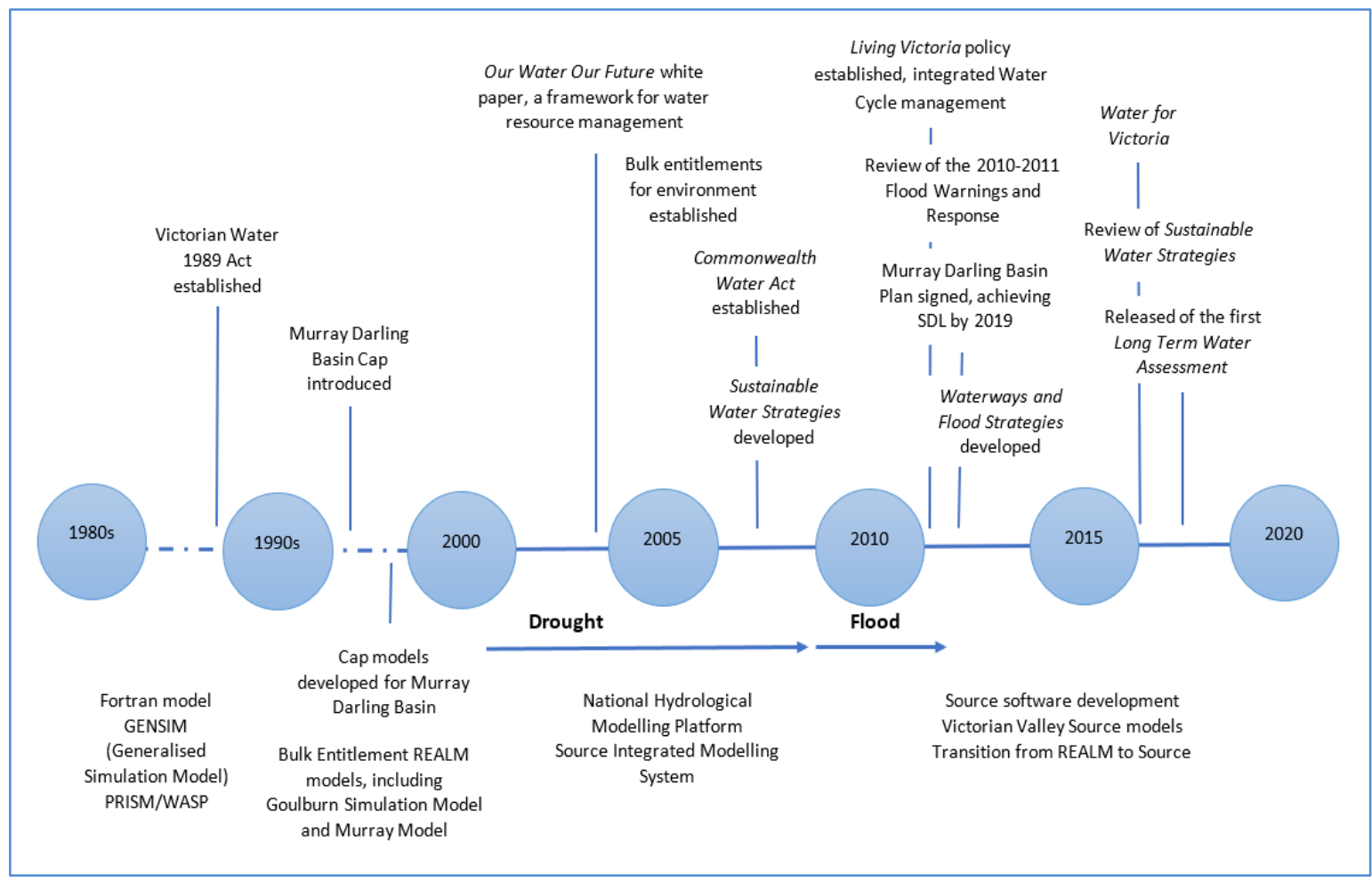

Figure 1. Key Reforms in Victorian Water Industry

\section{THE ROLE OF HYDROLOGIC MODELLING}

Through the process of water reform, hydrologic modelling has supported the development of water policy. Most importantly, it has provided a means to undertake a basin-wide hydrologic assessment of the water resource by quantifying the water availability and its variability in both time and space. For many years, the REALM software was used in Victoria to simulate all of the major Victorian water supply systems. The REALM software was developed in Fortran originally as a DOS program which was later developed to include a Windows user interface and was supported by DELWP and Victoria University.

The development of Victorian bulk entitlements involved creating a REALM model of each system. The models included time series of each of the significant inflows and diversions in each catchment and the water supply system operating practices and policies. The bulk entitlement process included significant community consultation. The modelling inputs and outputs provided a basis to demonstrate to stakeholders the impacts of various proposals and changes to policies that were considered during the process.

The Murray-Darling Basin Cap has successfully been used to ensure that diversions by jurisdictions are maintained within the cap. Hydrologic modelling is an integral part of the cap. Models of each of the cap valleys within the Murray-Darling Basin were created to represent 1993/94 level of development to simulate the long-term diversions from the Basin. The models are run on an annual basis to demonstrate the total diversions from each valley that would have occurred in that year in each valley if 1993/94 level of development conditions existed given the actual climate conditions in that year. These modelled cap diversions are then compared with actual recorded diversions in that year.

More recently, hydrologic models have provided the basis of the development of the Basin Plan, long term water availability assessments and inputs to sustainable water strategies including impacts of climate change projections, and long-term water resource assessment in Southern Victoria.

Water for Victoria (2016) describes Victoria's planned approach to improve water availability and use reporting. Hydrologic modelling helps to contribute to the desired outcomes which are:

- Improved water literacy

- An engaged and informed community

- $\quad$ Equitable and compliant water use and sharing

- Improved and timely decision-making

- Enabling strategic responses to water management challenges 
Mariyapillai et al., A vision for future hydrologic modelling to support Victoria's evolving water resource management

Hydrologic modelling supports the Victorian Government actions identified in Water for Victoria for:

- providing a well-functioning water market, with appropriate monitoring, transparency, frameworks and regulations, to help people adapt to change

- making sure that infrastructure remains viable and understanding the implications for the management of irrigation districts

- building awareness of water availability and delivery challenges and risks so people can make informed decisions and adapt.

The value of a well-functioning water market is high. The value of the northern Victoria water market alone is over $\$ 4$ billion. It is highly complex with interstate interactions. Modelling allows scenarios to be tested to allow an analysis of advantages and disadvantages of scenarios to guide policy development and investment decisions.

\section{HYDROLOGIC MODELLING REQUIREMENTS}

Victoria's hydrologic modelling requirements are continuing to develop as the water supply system and management changes. Software tools and technology are required to model the system as it is now and as it may be in the future. While the REALM software has proved to be a valuable tool to address needs of water reforms and policy developments in the past, it is not meeting current modelling criteria of consistency, transparency and defensibility required initially in the Murray-Darling Basin, and ultimately across Australia, for the reason that each jurisdiction is using its own preferred modelling software.

In order to plan for Victoria's modelling requirements, the State has supported the COAG endorsed National Hydrological Modelling Strategy (NHMS) since its initiation through funding and technical contribution. The NHMS defines objectives related to ensuring that Australia's hydrologic modelling capability, community and software is ready to meet the priority hydrological modelling needs of Australian governments.

The Source modelling platform, referred hereafter as Source software is a key deliverable of the NHMS. Source software has been designed and developed within Australia to provide a flexible, transparent, robust and repeatable approach to underpin a wide range of water planning and management activities by State and Commonwealth agencies. Victoria has implemented Source in many valleys including the foundational model of Goulburn, Broken, Campaspe, Coliban and Loddon system, and is developing Source models for most of the other parts of Victoria.

\section{FUTURE HYDROLOGIC MODELLING APPLICATIONS}

Looking forward, there is a need and an opportunity for the models to be developed and applied in a transparent, repeatable and defensible way to a wide range of complex applications as described below.

\subsection{Planning model to support water management practices}

Planning models are long term water resource models of water supply system that are used to simulate different operating policies and their impacts over the time. Historically planning models have provided insights for water managers to make policy and operational decisions. This will continue as planning models evolve to represent the complexity of the existing and future systems.

Planning models provide support for new policy development and business decisions and allow communication of issues to stakeholders and receive their feedback to the policy development process. A well-executed application of the model will enable all stakeholders to work collaboratively together to minimise duplication, allow cost sharing and improve accuracy of model projections.

\subsection{Alternatives sources for urban water supply}

The Melbourne Water System Strategy (2017) identifies as a priority the use of diverse sources of water including rainwater, stormwater and recycled water whenever the benefits outweigh the costs. Some consideration of issues involved includes:

- What volumes of rainwater, stormwater and recycled water are available in a given location?

- What is the quality of the available water, and how variable is it?

- How much water is actually needed by the community in a given location, and what proportion of that water demand can be safely and reliably met using rainwater, stormwater or recycled water? 
Mariyapillai et al., A vision for future hydrologic modelling to support Victoria's evolving water resource management

Such issues can be addressed using hydrologic modelling to investigate the interactions between the different sources of water and the water supply system.

\subsection{Catchment modelling of climate change and land use change}

Modelling of climate change impacts often involves utilising climate change projections impact on rainfall and evaporation to simulate the change in runoff to waterways and water supply systems. The modelling of rainfall-runoff processes involves modelling of the physical catchment processes which depend on given land use and can be impacted by land use change. The ability to bring together modelling catchment processes with river network and water supply system modelling offers the opportunity to explore these interactions.

\subsection{Operational model for flow forecasting}

An operational model can be used for flow forecasting. Such a model may input live data feeds from the Bureau of Meteorology climate data to drive rainfall runoff models to forecast catchment inflows. Stakeholders may include environmental water managers, water corporations, irrigators and energy companies.

\subsection{Combined planning and operational model for the water grid}

Victoria's water grid connects water supply systems including reservoirs and rivers with infrastructure including pipes and pumps to allow water resources to be moved or traded from one system to another. Victoria's water grid is part of a wider grid that extends interstate to NSW and South Australia. A planning and operational tool could support the management of the movement of water through the water grid across the jurisdictions to meet competing water demand amid varying water availability.

\subsection{Tool for compliance}

At a basin or state level, diversion compliance requires modelling as has been undertaken for the MurrayDarling Cap for more than twenty years. Similarly, the Basin Plan requires modelling of the sustainable diversion limit for annual compliance purposes.

\subsection{Water quality assessments}

Simulation of water quality constituents is required to enable assessments of changes such as land use impact on river systems. Water quality constituents include salinity, total suspended sediments (TSS), total nitrogen (TN) and total phosphorus (TP). Salinity generation and salt wash off processes together with the routing of salinity in river systems can be included in existing models to allow assessment of salinity impacts. Such assessments are required to meet Victoria's commitment to the Basin Management Strategy 2030. Modelling of TSS, TN and TP can be achieved using Source catchments functionality and plug-in functionality as required.

\subsection{Environmental flow delivery, flooding issues, easements and delivery capacity.}

As environmental holdings have increased significantly in the past decade, issues related to the management of environmental deliveries are becoming better understood. The models can be used to evaluate different environmental flow demand and delivery strategies including associated flooding issues such as requirement for flooding easements and delivery capacity of rivers.

\section{FUTURE CHALLENGES}

Some of the challenges for modelling in the future includes modelling the increasingly complex supply systems and a wider range of impacts, maintaining modelling capability and ongoing software development.

\subsection{Modelling increasingly complex supply systems}

As water supply systems have become more complex with the removal of boundaries to the supply of water due to water trade, challenges to model the systems have arisen. The movement of water from one area to another depends on many factors, some of which are external to a traditional water resources model. Not only does trade depend on water availability and water prices in different systems, other drivers include commodity prices and agricultural gross margins for different crops. 
Mariyapillai et al., A vision for future hydrologic modelling to support Victoria's evolving water resource management

\subsection{Hydrologic modelling to support analysis of wider impacts}

As the physical supply systems continue to become more complex, opportunities and challenges exist to continue to further develop hydrologic modelling approaches to improve the ability to evaluate wider system impacts. For example, the complexity of delivering environmental flows to multiple sites for multiple objectives from multiple sources provides modelling challenges regarding the water supply system itself and also including characterising flow related ecological benefits. As environmental monitoring and research continues to increase knowledge, continued development of methods to represent ecological and biophysical processes that occur in river systems and wetlands can be further embedded into hydrologic modelling approaches. Similarly, as further research and knowledge is gathered on socioeconomic impacts and cultural values of water, the role of hydrologic modelling to support the assessment of these impacts will need to continue to evolve.

\subsection{Maintaining modelling capability}

Maintaining modelling capability across the water industry requires investment of time by those already in the modelling community and by those entering the community. There is much for modellers to learn about not only about best practice modelling approaches but also the details of the varied water resource systems across the state, each with their own unique hydrological and management properties. Maintaining modelling capability can be a challenge as work practices change as the workforce becomes more mobile and gained experience can be lost. Knowledge transfer practices and the development of the modelling community of practice can help mitigate loss of individual capability.

A related issue is the ease of use and how intuitive the software and the models built within the software are for new users to be able to modify and run the model. The ability of users who may not have in-depth modelling experience or system understanding to begin to apply the model under guidance from more senior practitioners is important aspect of the continual building modelling capability.

\subsection{Software development}

The process of software development for water resources modelling software has changed. For many years the software was developed by professional hydrologists and water resources engineers who wrote and maintained the software code and the user interface. Three major software platforms for modelling water resources in Australia included REALM, MSM-Bigmod and IQQM which were all largely written and maintained by hydrologists.

The Source software has been written and developed by professional software developers in association with hydrologists. This process began in the eWater CRC and has continued with eWater Ltd. The benefits of this process include the ongoing development and support of a professionally developed modern piece of software. A challenge for modellers is to identify future modelling requirements and ensure that the software developers are aware of emerging requirements and understand why they are required and any specific model functionality which may be required.

\subsection{Leverage modelling investment to timely and tailored information}

In addition to the advances in software development there has been significant investment in modern water data collection and dissemination systems. There is an opportunity to leverage these capabilities to provide enhanced real-time water information that is tailored to water users. This will require automation of model input data preparation, cloud-based model development and application and development of data visualisation tools.

\section{CONCLUSIONS AND RECOMMENDATIONS}

Source is a modern software platform, hence ongoing development and improvement can be accommodated as new requirements arise to meet industry modelling needs. A challenge for future modelling is the representation of the current system and its complexity including modelling water trade, environmental requirements in a system with no boundaries, a continuously changing landscape and modelling the accounting of water across all water users. Besides the challenges in future modelling from the perspective of physical and operational complexities, it is expected that the next generation of hydrological models, that leverage Source software will provide a mechanism to explicitly or implicitly support analysis of a wide range of impacts of water management. 
Mariyapillai et al., A vision for future hydrologic modelling to support Victoria's evolving water resource management

\section{ACKNOWLEDGEMENTS}

Authors acknowledge work undertaken by Yong Li for the development of Source daily model of Goulburn, Broken, Campaspe, Coliban and Loddon valleys ( $\mathrm{Li}$ et al. 2019), and her significant contribution in hydrological testing of Source functionality, including provision of technical inputs for the development of many Source functionality.

\section{REFERENCES}

Li, Y., Manandhar, U. and Mariyapillai, S. (2019). Source adoption in Northern Victoria: a hydrological model of an integrated Goulburn, Broken, Campaspe, Coliban and Loddon rivers system (in preparation).

Melbourne Water (2017). Melbourne Water system strategy, March 2017.

Tisdell, J., Ward, J. and Grudzinski, T. (2002). The development of water reform in Australia. Cooperative Research Centre for Catchment Hydrology Technical Report, Report 02/5 May 2002.

Victorian State Government (2016). Water for Victoria, Water Plan (www.water.vic.gov.au). 